\title{
Características de fermentação da silagem de seis variedades de milho indicadas para a região semiárida brasileira
}

[Fermentation parameters of silages of six maize varieties recommended for the Brazilian semi-arid region]

R.D. Santos ${ }^{1,2}$, L.G.R. Pereira ${ }^{3}$, A.L.A. Neves $^{3}$, G.G.L. Araújo ${ }^{2}$, T.V. Voltolini ${ }^{2}$, L.G.N. Brandão ${ }^{4}$, A.S.L. Aragão ${ }^{1}$, J.R.R. Dórea ${ }^{5}$

\author{
${ }^{1}$ Aluno de pós-graduação - UNIVASF - Petrolina, PE \\ ${ }^{2}$ Embrapa Semiárido \\ Caixa Postal 23 \\ 56302-970 - Petrolina, PE \\ ${ }^{3}$ Embrapa Gado de Leite - Juiz de Fora, MG \\ ${ }^{4}$ FTC - Feira de Santana, BA \\ ${ }^{5}$ Aluno de pós-graduação - ESALQ/USP - São Paulo, SP
}

\begin{abstract}
RESUMO
Avaliaram-se as características fermentativas e a qualidade das silagens de seis variedades de milho, de ciclos precoce e superprecoce - BRS Caatingueiro, BRS Assum Preto, BR 5033 Asa Branca, BR 5028 São Francisco, Gurutuba e BRS 4103 - indicadas para a região semiárida brasileira. Foram utilizados silos experimentais, em delineamento inteiramente ao acaso, com seis tratamentos (variedades) e quatro repetições. Avaliaram-se: matéria seca (MS), matéria orgânica (MO), proteína bruta (PB), fibra em detergente neutro (FDN), fibra em detergente ácido (FDA), extrato etéreo (EE), carboidratos totais (CHO), carboidratos não fibrosos (CNF), pH, nitrogênio amoniacal como parte do nitrogênio total $\left(\mathrm{N}-\mathrm{NH}_{3} / \mathrm{NT}\right)$, ácidos orgânicos e digestibilidade in vitro da matéria seca (DIVMS) das silagens. Os valores médios encontrados para a silagem foram: $\mathrm{MS}=28,7 \%$; $\mathrm{MO}=$ 94,9\%; $\mathrm{PB}=8,3 \% ; \mathrm{FDN}=49,9 \% ; \mathrm{FDA}=27,5 \% ; \mathrm{EE}=3,8 \% ; \mathrm{CHO}=82,7 \% ; \mathrm{CNF}=32,8 \% ; \mathrm{pH}=3,8 ; \mathrm{N}-$ $\mathrm{NH}_{3} / \mathrm{NT}=2,9 \% / \mathrm{NT}$; ácido láctico = 7,6\%; ácido acético = 0,6\%; ácido butírico = 0,3\% e DIVMS= 57,9\%. As variedades BR 5028 - São Francisco e Gurutuba destacaram-se das demais em relação ao teor de matéria seca. A variedade BRS Caatingueiro apresentou maior teor de carboidratos não fibrosos em relação às demais. As silagens de todas as variedades foram classificadas como de excelente qualidade, por apresentarem potencial para ensilagem no semiárido brasileiro.
\end{abstract}

Palavras-chave: silagem, milho, ácidos orgânicos, digestibilidade in vitro, ruminantes

\begin{abstract}
The fermentation characteristics and silage quality of six maize varieties of early and super early cycles were evaluated. They are recommended for the Brazilian semi-arid region (BRS Caatingueiro, BRS Assum Preto, BR 5033 - Asa Branca, BR 5028 - São Francisco, Gurutuba and BRS 4103). Experimental silos were used, in a completely randomized design, with six treatments (varieties) and four replicaties. The evaluated parameters were: dry matter (DM), organic matter (OM), crude protein (CP), neutral detergent fiber (NDF), acid detergent fiber ( $A D F)$, ether extract (EE), total carbohydrates (CHO), non-fibrous carbohydrates (NFC), $p H$, ammoniacal nitrogen as part of the total nitrogen $\left(\mathrm{N}-\mathrm{NH}_{3} / \mathrm{TN}\right)$, organic acids, and in vitro dry matter digestibility (IVDMD) of the silages. The mean values found for silage were: $D M=29.6 \%$; OM=94.9\%; $C P=$ $8.2 \% ; N D F=49.9 \% ; A D F=27.5 \% ; E E=3.8 \% ; C H O=82.7 \% ; N F C=32.8 \% ; p H=3.8 ; N-N H_{3} / T N=$ $2.9 \% / T N$; lactic acid $=7.6 \%$; acetic acid $=0.6 \%$; butyric acid $=0.3 \%$; and IVDMD $=57.9 \%$. Varieties $B R$ 5028 - São Francisco and Gurutuba stood out $(P<0.05)$ from others in relation to dry matter. The BRS Caatingueiro showed higher $(P<0.05)$ level of non-fiber carbohydrates in relation to the others. The silages from all the varieties were considered of excellent quality, with potential to be conserved as silage in the Brazilian semi-arid.
\end{abstract}

Keywords: silage, corn, organic acids, in vitro digestibility, ruminants

Recebido em 26 de dezembro de 2009

Aceito em 11 de outubro de 2010

E-mail: rafael.dantas@cpatsa.embrapa.br 


\section{INTRODUÇÃo}

A estacionalidade produtiva de forragens de boa qualidade, assim como a necessidade de atender à produção de ruminantes no Nordeste brasileiro, impulsiona os produtores do semiárido a adotarem práticas de conservação de forragens, destacando-se para esse propósito o processo de ensilagem. Ferrari Jr. et al. (2005) afirmaram que o milho apresenta-se como uma das melhores opções para o processo de ensilagem, pois possui elevado teor de carboidratos solúveis para fermentação, elevada produção de matéria seca por unidade de área, pequena capacidade tampão e elevado valor nutritivo. Deve-se acrescentar, ainda, que é uma espécie de cultivo tradicional, muito difundida no meio rural nordestino, com importância econômica, social e cultural.

O sucesso na produção de silagem, todavia, depende do grau de adaptação dos diferentes genótipos frente às características edafoclimáticas da área de cultivo. A falta de informações regionais pertinentes ao comportamento agronômico produtivo e ao valor nutritivo dos diversos materiais genéticos existentes no mercado tornou-se um obstáculo quanto ao melhor planejamento da escolha das variedades de milho que se destinem à produção de silagem no semiárido.

Segundo Van Soest (1994), a qualidade da silagem pode ser influenciada, entre outros fatores, pelo processo fermentativo da massa, uma vez que, durante a ensilagem, pode ocorrer redução do valor nutritivo pela respiração, fermentação aeróbia, processos de decomposição ou perdas de efluentes. Entre os parâmetros que determinam a qualidade da fermentação, estão os valores de $\mathrm{pH}$ associados ao teor de matéria seca e a concentração de nitrogênio amoniacal em relação ao nitrogênio total $\left(\mathrm{N}-\mathrm{NH}_{3} / \mathrm{NT}\right)$.

Os valores de $\mathrm{pH}$ estão relacionados às concentrações de carboidratos solúveis na forragem a ser ensilada, pois estes contribuem para a produção de ácidos orgânicos, principalmente ácido láctico, que são importantes para obtenção de boa silagem. A acidez atua diminuindo a atividade proteolítica ocasionada por enzimas da própria planta e, ainda, controlando ou inibindo o desenvolvimento de microrganismos indesejáveis e também da própria atividade das bactérias produtoras de ácido láctico (Tomich et al., 2003). A presença de nitrogênio amoniacal também é uma característica importante na avaliação da silagem, pois contribui para a elevação do $\mathrm{pH}$, sendo, por isso, indicativo de fermentação indesejável (McDonald et al., 1991).

Diversas variedades e híbridos de milho estão disponíveis no mercado, no qual se observam grandes variações quanto à produção e concentração de nutrientes, tornando importantes os estudos comparativos que avaliem as características nutricionais destes cultivares assim como a influência destas características na qualidade da silagem produzida. A necessidade desses estudos é reforçada quando os genótipos a serem avaliados são indicados para uma região com particularidades únicas, como a região semiárida nordestina, e principalmente pelo fato de os genótipos disponíveis no mercado não terem sido avaliados na forma de silagem.

O objetivo deste trabalho foi avaliar as características fermentativas e a qualidade das silagens de seis variedades de milho de ciclos precoce ou superprecoce, indicadas para a região semiárida nordestina.

\section{MATERIAL E MÉTODOS}

O experimento foi realizado na Embrapa Semiárido, em Petrolina-PE, localizada na região do Submédio do Vale do São Francisco, a uma latitude de $09^{\circ} 09^{\prime} \mathrm{S}$, longitude de $40^{\circ} 22^{\prime} \mathrm{W}$, altitude de $365,5 \mathrm{~m}$ e média pluviométrica anual de $570 \mathrm{~mm}$, com temperaturas médias anuais de máximas e mínimas de 33,46 e $20,87^{\circ} \mathrm{C}$, respectivamente, no período de setembro/2007 a janeiro/2008. O delineamento experimental utilizado foi inteiramente ao acaso, com seis tratamentos e quatro repetições. Os tratamentos constituíram-se de seis variedades de milho indicadas para a região semiárida nordestina: BR 5033 - Asa Branca, BR 5028 - São Francisco, BRS 4103, BRS Caatingueiro, BRS Assum Preto e Gurutuba, sendo os três primeiros de ciclo precoce, e os demais de ciclo superprecoce.

Inicialmente, para o estabelecimento da cultura de milho, a área foi arada e, posteriormente, gradeada para destorroamento, nivelamento e abertura de sulcos espaçados de $1 \mathrm{~m}$. A adubação foi realizada baseada na análise do solo, sendo necessárias duas adubações de cobertura com 
$60 \mathrm{~kg}$ de N/ha aos 30 e 45 dias após a emergência, além de duas aplicações de inseticidas para controle de pragas. Vinte e dois dias após a emergência, procedeu-se ao desbaste das plantas deixando-se uma população aproximada de 55.000 plantas/ha. As silagens de cada variedade foram obtidas de quatro diferentes canteiros experimentais de $12 \mathrm{~m}^{2}$ de área útil cada.

As plantas, colhidas quando apresentavam grãos no estádio farináceo duro, foram cortadas rente ao solo, amontoadas e picadas em ensiladeira estacionária, ajustada para produção de partículas de aproximadamente $2 \mathrm{~cm}$. Para a obtenção das silagens, utilizaram-se silos experimentais, feitos de canos de PVC, com $10 \mathrm{~cm}$ de diâmetro e $40 \mathrm{~cm}$ de comprimento, com capacidade para, aproximadamente, 3,5 a 4,0kg. O material foi compactado manualmente.

Os silos foram abertos 56 dias após o armazenamento. As amostras das silagens após abertura dos silos foram pré-secas em estufa de ventilação forçada a $60^{\circ} \mathrm{C}$ por $72 \mathrm{~h}$ e processadas em moinhos com peneiras de crivos de $1 \mathrm{~mm}$ de diâmetro. As amostras processadas foram acondicionadas em frascos de polietileno para determinação dos teores de matéria seca (MS), matéria orgânica (MO), proteína bruta (PB), fibra em detergente neutro (FDN), fibra em detergente ácido (FDA) e extrato etéreo (EE), de acordo com as recomendações de Silva e Queiroz (2002), e digestibilidade in vitro da matéria seca (DIVMS), de acordo com o método das duas etapas de Tilley e Terry (1963), descritas por Silva e Queiroz (2002).

Os teores de carboidratos totais (CHO) e carboidratos não fibrosos (CNF) foram obtidos pelas equações: $\mathrm{CHOT}=100-(\mathrm{PB} \%+\mathrm{EE} \%+$ $\mathrm{MM} \%)$ e $\mathrm{CNF}=100-(\mathrm{PB} \%+\mathrm{EE} \%+\mathrm{MM} \%+$ FDN\%).

Determinaram-se, ainda, o $\mathrm{pH}$, os teores de nitrogênio amoniacal como parte do nitrogênio total $\left(\mathrm{N}-\mathrm{NH}_{3} / \mathrm{NT}\right)$, e ácidos orgânicos (láctico, acético e butírico) para a classificação quanto à qualidade das silagens. Para isto, imediatamente após a abertura dos silos, com auxílio de prensa manual, foi obtido o suco da silagem, o qual foi utilizado para determinar o $\mathrm{pH}$ com auxílio de um potenciômetro de hidrogênio. O teor de nitrogênio amoniacal em relação ao nitrogênio total $\left(\mathrm{N}-\mathrm{NH}_{3} / \mathrm{NT}\right)$ foi dosado após destilação com óxido de magnésio e cloreto de cálcio (Official..., 1995).

Para análise dos ácidos orgânicos, foram adotadas as recomendações de Kung Junior e Ranjit (2001). Em 2mL do filtrado, adicionou-se $1 \mathrm{~mL}$ de ácido metafosfórico $20 \% \mathrm{v} / \mathrm{v}$, sendo essa amostra centrifugada. As análises dos ácidos orgânicos (ácido láctico, ácido acético e ácido butírico) foram efetuadas por cromatografia líquida de alta resolução (HPLC).

Os parâmetros de qualificação das silagens adotados no presente trabalho foram os sugeridos por Tomich et al. (2003). Os autores sugeriram critérios de pontuação de acordo com os valores encontrados para características químicas da silagem como o $\mathrm{pH}$ associado ao teor de MS, N$\mathrm{NH}_{3} / \mathrm{NT}$ e os teores de ácido butírico e ácido acético.

As variáveis foram testadas para verificar a ocorrência de distribuição normal antes de se proceder à análise de variância. As médias foram comparadas pelo teste Tukey a 5\% de probabilidade $(\mathrm{P}<0,05)$, sendo analisadas no programa SAS (SAS, 2002).

\section{RESULTADOS E DISCUSSÃO}

Foram observadas diferenças $(\mathrm{P}<0,05)$ para os teores de MS, PB, FDN, FDA e DIVMS (Tab. 1).

As variedades BR 5028 São Francisco e Gurutuba apresentaram maiores teores $(\mathrm{P}<0,05)$ de MS em relação às demais variedades. Apesar das diferenças $(\mathrm{P}<0,05)$ entre as variedades, os teores de MS obtidos neste ensaio estão próximos a $28 \%$, valor indicado como ideal para silagens de forrageiras tropicais (McDonald et al., 1991). Resultados próximos foram obtidos por Jaremtchuk et al. (2005), para 20 genótipos de milho, na região leste paranaense (média de 29,1\% de matéria seca). Para se obter silagens de milho com teores adequados de matéria seca, as plantas devem ser cortadas quando os grãos se encontram entre as texturas pastosa e farinácea dura. 
Santos et al.

Tabela 1. Composição bromatológica de variedades de milho

\begin{tabular}{lllllllll} 
Item & 5033 & 5028 & 4103 & APR & GTB & CTG & Media & CV \\
\hline MS & $28,3 \mathrm{~b}$ & $30,0 \mathrm{a}$ & $27,8 \mathrm{~b}$ & $26,9 \mathrm{c}$ & $30,0 \mathrm{a}$ & $29,3 \mathrm{~b}$ & 28,7 & 4,3 \\
MO & 95,1 & 95,3 & 95,6 & 94,5 & 94,3 & 94,6 & 94,9 & 3,9 \\
PB & $8,9 \mathrm{a}$ & $7,6 \mathrm{c}$ & $8,5 \mathrm{ab}$ & $8,2 \mathrm{abc}$ & $8,6 \mathrm{ab}$ & $8,1 \mathrm{bc}$ & 8,3 & 3,4 \\
FDN & $50,2 \mathrm{~b}$ & $54,0 \mathrm{a}$ & $50,1 \mathrm{~b}$ & $47,6 \mathrm{~b}$ & $50,1 \mathrm{~b}$ & $47,6 \mathrm{~b}$ & 49,9 & 2,7 \\
FDA & $24,9 \mathrm{c}$ & $29,8 \mathrm{a}$ & $26,0 \mathrm{bc}$ & $28,5 \mathrm{a}$ & $26,9 \mathrm{~b}$ & $29,0 \mathrm{a}$ & 27,5 & 2,2 \\
CHO & $82,0 \mathrm{de}$ & $84,0 \mathrm{a}$ & $83,2 \mathrm{~b}$ & $82,4 \mathrm{~cd}$ & $81,7 \mathrm{e}$ & $82,9 \mathrm{bc}$ & 82,7 & 0,2 \\
CNF & $31,8 \mathrm{~d}$ & $30,0 \mathrm{e}$ & $33,1 \mathrm{c}$ & $34,8 \mathrm{~b}$ & $31,6 \mathrm{~d}$ & $35,3 \mathrm{a}$ & 32,8 & 0,4 \\
EE & $4,1 \mathrm{a}$ & $3,7 \mathrm{ab}$ & $3,9 \mathrm{a}$ & $3,8 \mathrm{ab}$ & $4,0 \mathrm{a}$ & $3,5 \mathrm{~b}$ & 3,8 & 1,3 \\
DIVMS & 61,0a & $56,0 \mathrm{~b}$ & $57,3 \mathrm{ab}$ & $58,3 \mathrm{ab}$ & $56,0 \mathrm{~b}$ & $59,0 \mathrm{ab}$ & 57,9 & 6,2 \\
\hline
\end{tabular}

Médias, na coluna, seguidas de letras diferentes, diferem entre si $(\mathrm{P}<0,05)$ pelo teste Tukey.

5033: BR 5033 Asa Branca; 5028: BR 5028 São Francisco; 4103: BRS 4103; APR: BRS Assum Preto; GTB: Gurutuba; CTG: BRS Caatingueiro.

MS: matéria seca (\%); MO: matéria orgânica (\%); PB: proteína bruta (\% da MS); FDN: fibra em detergente neutro (\% da MS); FDA: fibra em detergente ácido (\% da MS); CHO: carboidratos totais (\% da MS); CNF: carboidratos não fibrosos (\% da MS); EE: extrato etéreo (\% da MS); DIVMS: digestibilidade in vitro da matéria seca (\%).

CV: coeficiente de variação em \%.

Quanto aos teores de PB, a variedade BR 5033 Asa Branca, a de maior teor de $\mathrm{PB}$, diferiu $(\mathrm{P}<0,05)$ apenas das variedades BRS Caatingueiro e BR 5028 São Francisco, porém a variedade BR 5033 Asa Branca não diferiu $(\mathrm{P}>0,05)$ das variedades Gurutuba, BRS 4103 e BRS Assum Preto. Além disso, as variedades Gurutuba, BRS 4103 e BRS Assum Preto não diferiram da $(\mathrm{P}>0,05)$ da variedade BRS Caatingueiro e as variedades BRS Assum Preto, BRS Caatingueiro e BR 5028 São Francisco também não diferiram $(\mathrm{P}>0,05)$ entre si. Os valores encontrados foram mais elevados que os obtidos por Filya (2003), que observou médias de $6,1 \%$ e $5,8 \%$, para silagens de dois genótipos de milho, utilizadas em regiões semiáridas turcas.

A observação dos teores de fração fibrosa das silagens é de fundamental importância para o conhecimento do valor nutritivo desses alimentos para ruminantes, pois esta fração do alimento fornece quantidade significativa de energia a baixo custo, destacando-se na avaliação de disponibilidade de energia (Detmann et al., 2004). Os teores de FDN e FDA são indicativos da quantidade de fibra da forragem, estando a FDN relacionada à quantidade de fibra que há no volumoso, enquanto a FDA à quantidade de fibra menos digestível; desse modo, quanto menor os teores, melhor será a qualidade da silagem produzida e maior será o consumo de MS. O maior valor $(\mathrm{P}<0,05)$ de FDN nas silagens foi observado na variedade precoce BR 5028 - São
Francisco (54\%), destacando-se das demais $(\mathrm{P}<0,05)$, que não diferiram entre si $(\mathrm{P}>0,05)$.

Para a FDA, os teores mais altos foram observados nas variedades BR 5028 São Francisco, BRS Caatingueiro e BRS Assum Preto, com valores de 29,8, 29,0 e 28,5\%, respectivamente, as quais não diferiram entre si $(\mathrm{P}>0,05)$, mas diferiram das demais $(\mathrm{P}<0,05)$. Os teores mais baixos $(\mathrm{P}<0,05)$ de FDA foram para as variedades BR 5033 Asa Branca e BRS 4103, que não diferiram entre si $(\mathrm{P}>0,05)$, porém a variedade BRS 4103 também não diferiu $(\mathrm{P}>0,05)$ da variedade Gurutuba. Os teores médios de FDN e FDA obtidos neste experimento são mais baixos que os encontrados por Pedroso et al. (2006), que avaliaram oito híbridos de milho e obtiveram médias de 62,5\% e 37,9\%, para FDN e FDA, respectivamente. Senger et al. (2005) observaram teores de 51,6\% para FDN e $28 \%$ para FDA, quando estudaram silagem de híbrido de milho com 28\% de matéria seca.

A variedade BR 5028 São Francisco apresentou maior $(\mathrm{P}<0,05)$ teor de carboidratos totais $\mathrm{e}$ diferiu das demais variedades. Pereira et al. (2007) observaram valores médios de 87,7\% para teores de carboidratos totais nas silagens de híbridos de milho produzidas em silos experimentais.

Para o teor de carboidratos não fibrosos, destacou-se $(\mathrm{P}<0,05)$ dos demais a variedade superprecoce BRS Caatingueiro. Senger et al. 
(2005), ao avaliarem silagem de milho com $28 \%$ de MS, observaram teores médios de $32,6 \%$ de carboidratos não fibrosos, sendo estes valores semelhantes aos obtidos neste ensaio. Valores semelhantes foram observados por Cabral et al. (2004), que relataram 31,2\% de carboidratos não fibrosos em silagem de milho.

Em relação aos teores de EE, as variedades BR 5033 Asa Branca, Gurutuba e BRS 4103 diferiram $(\mathrm{P}<0,05)$ apenas da variedade $\mathrm{BRS}$ Caatingueiro, porém as variedades BRS Assum Preto e BR 5028 São Francisco não diferiram $(\mathrm{P}>0,05)$ das demais. Ferrari Jr. et al. (2005) reportaram teores de extrato etéreo que variaram de 3,1 a 3,8\% quando avaliaram oito cultivares para produção de silagem.

A DIVMS das silagens variou de 56,0 a $61,0 \%$, sendo observado que as variedades BR 5028 São Francisco e Gurutuba apresentaram valores mais baixos $(\mathrm{P}<0,05)$ em relação à variedade BR 5033 Asa Branca, porém essas três variedades não diferiram $(\mathrm{P}>0,05)$ das demais. Valadares Filho et al. (2006) apresentaram, na Tabela Brasileira de Composição de Alimentos, valor médio de $58,4 \%$ quanto à DIVMS, a partir de dados originados de 29 amostras. No entanto, Mello et al. (2005), ao avaliarem cinco híbridos de milho de ciclo precoce e superprecoce, na depressão central do Rio Grande do Sul, obtiveram média superior à deste ensaio $(63,4 \%)$ para a DIVMS. Abdelhadi et al. (2005) observaram média de 60\% de DIVMS, ao avaliarem híbridos de milho no sul da Argentina.

Os resultados dessas variedades indicadas para o semiárido equiparam-se aos de genótipos tradicionalmente utilizados para produção de silagem, cultivados em regiões sem limitações hídricas, sendo um indicativo do potencial de conservação dessas variedades na forma de silagem.

Quanto aos parâmetros utilizados para avaliar a qualidade do processo fermentativo (Tab. 2), foram observadas diferenças $(\mathrm{P}<0,05)$ nos teores de nitrogênio amoniacal como parte do nitrogênio total $\left(\mathrm{N}-\mathrm{NH}_{3} / \mathrm{NT}\right)$ e nos teores de ácido acético, e não ocorreu o mesmo para $\mathrm{pH}$ e teores de ácido lcático e butírico (P>0,05), os quais apresentaram médias de 3,8, 7,5\% da MS e $0,3 \%$ da MS, respectivamente.

Tabela 2. Valores médios de pH e nitrogênio amoniacal (N-NH$/ \mathrm{NT})$ e teores dos ácidos láctico, acético e butírico nas silagens de seis variedades de milho

\begin{tabular}{llllll}
\hline Variedade & $\mathrm{pH}$ & $\mathrm{N}^{-\mathrm{NH}_{3} / \mathrm{NT}}$ & Láctico & Acético & Butírico \\
\hline BRS Caatingueiro & 3,8 & $3,0 \mathrm{~b}$ & 6,9 & $0,6 \mathrm{~b}$ & 0,3 \\
BRS Assum Preto & 3,8 & $3,7 \mathrm{a}$ & 9,3 & $0,5 \mathrm{~b}$ & 0,3 \\
BR 5033 Asa Branca & 3,7 & $2,8 \mathrm{~b}$ & 7,6 & $0,7 \mathrm{ab}$ & 0,3 \\
BR 5028 São Francisco & 3,8 & $2,5 \mathrm{~b}$ & 7,9 & $0,8 \mathrm{a}$ & 0,3 \\
Gurutuba & 3,9 & $2,7 \mathrm{~b}$ & 6,9 & $0,7 \mathrm{ab}$ & 0,3 \\
BRS 4103 & 3,7 & $2,7 \mathrm{~b}$ & 6,5 & $0,6 \mathrm{~b}$ & 0,3 \\
\hline Média & 3,8 & 2,9 & 7,5 & 0,6 & 0,3 \\
\hline CV (\%) & 2,7 & 10,4 & 17,7 & 17,4 & 27,4 \\
\hline
\end{tabular}

Médias, na coluna, seguidas de letras diferentes, diferem entre si $(\mathrm{P}<0,05)$ pelo teste Tukey.

Os valores de $\mathrm{pH}$ estão dentro da faixa considerada ideal $(3,6$ a 4,2) para promover uma eficiente conservação da massa ensilada (McDonald et al., 1991). Os valores médios entre 3,7 e 3,9 estão próximos de 3,9 encontrados por Contreras-Govea et al. (2009) e de 3,7 observados por Nishida et al. (2007), que avaliaram a qualidade de silagens de milho nos Estados Unidos e no Japão, respectivamente.

$\mathrm{O}$ teor de $\mathrm{N}-\mathrm{NH}_{3} / \mathrm{NT}$ da variedade BRS Assum Preto foi mais alto que os das demais silagens $(\mathrm{P}<0,05)$, entretanto nenhuma das variedades apresentou mais do que $10 \%$ de $\mathrm{N}-\mathrm{NH}_{3} / \mathrm{NT}$, teor máximo admitido para silagens de boa qualidade (Characterization..., 1987). O nitrogênio amoniacal, expresso em porcentagem do nitrogênio total, indica a quantidade de proteína degradada durante a fase de fermentação. Portanto, esse parâmetro é um dos mais importantes na determinação da qualidade do processo fermentativo da massa ensilada. Segundo McDonald et al. (1991), silagens mal preservadas apresentam teores de amônia superiores a $10 \%$, sendo a amônia derivada do catabolismo de aminoácidos. 
Pereira et al. (2007) encontraram para silagem de milho valor médio de $1,9 \%$ para $\mathrm{N}-\mathrm{NH}_{3} / \mathrm{NT}$, resultado mais baixo que os encontrados neste ensaio. Porém, Rosa et al. (2004) observaram maior valor para $\mathrm{N}-\mathrm{NH}_{3} / \mathrm{NT}$ (6,2\%), quando avaliaram três híbridos de milho.

Os teores de ácido láctico em todas as silagens indicam o bom perfil fermentativo do material, pois este é o principal responsável pela redução do pH. Calabro et al. (2005) encontraram variação entre 4,5\% e 5,4\% na MS, quando avaliaram seis genótipos de milho, em províncias do sul da Itália. Os resultados deste ensaio, também, foram mais altos que o registrado por Donmez et al. (2003), 1,7\% para silagem de milho.

Os valores de ácido láctico encontrados variaram de 6,5 a 9,3\% da MS e são indicativos de silagens de qualidade. Jensen et al. (2005) observaram variação de 3,8 a 5,6\% de ácido láctico (em \% da MS), ao avaliarem a qualidade da silagem de milho utilizada na alimentação de bovinos leiteiros na Dinamarca.

Segundo McDonald et al. (1991), a presença do ácido acético em teores acima de $2 \%$ pode demonstrar a ação de enterobactérias e reduzir o consumo da silagem pelos animais. Os teores desse ácido diferiram entre as variedades $(\mathrm{P}<0,05)$ : BR 5028 São Francisco apresentou maiores valores $(\mathrm{P}<0,05)$ em relação à $\mathrm{BRS}$ Assum Preto, BRS Caatingueiro e à BRS 4103, sendo que, entre as demais, os teores foram semelhantes $(\mathrm{P}>0,05)$. Os valores para concentração de ácido acético estão abaixo dos valores obtidos por Costa et al. (2000), que encontraram variação entre $1,01 \%$ e $1,55 \%$ na MS, e por Ferrari Jr. et al. (2005), que observaram valores entre $1,06 \%$ e $2,0 \%$ na MS, ambos avaliando genótipos indicados para as regiões Sudeste e Sul, respectivamente.

O teor de ácido butírico reflete a extensão da atividade clostridiana e está relacionado a maiores valores finais de $\mathrm{pH}$. Valores abaixo de $0,3 \%$ indicam menores perdas de energia e matéria seca, segundo Tomich et al. (2003). Desse modo, os valores observados neste ensaio são característicos do perfil de fermentação típico de silagens de milho de excelente qualidade.
De acordo com a proposta de qualificação da fermentação de silagens, sugerida por Tomich et al. (2003), as silagens de todas as variedades receberam a qualificação excelente, pois todas obtiveram pontuação acima de 90 pontos.

Valadares Filho et al. (2006) reportaram na Tabela Brasileira de Composição de Alimentos valores médios de 3,8, 8,0\%, 4,90\%, 1,2\% e 0,04\%, para $\mathrm{pH}$, nitrogênio amoniacal como parte do nitrogênio total $\left(\mathrm{N}-\mathrm{NH}_{3} / \mathrm{NT}\right)$, ácido láctico, ácido acético e ácido butírico, respectivamente, em silagens com aproximadamente $31 \%$ de MS. Conforme os critérios sugeridos por Tomich et al. (2003), os valores médios nacionais permitiriam qualificação de excelente qualidade. A qualificação das silagens deste ensaio merece destaque por se tratar de silagens provenientes de variedades de milho indicadas para a região semiárida e por elas possuírem similaridade com os resultados obtidos quando se avaliam genótipos de milho tradicionalmente utilizados para produção de silagens. A avaliação e as respostas obtidas confirmam a possibilidade de difusão dessas variedades, indicadas inicialmente para produção de grãos, também para produção de silagem no semiárido, zona carente de opções forrageiras e com peculiaridades regionais marcantes.

\section{CONCLUSÕES}

As variedades avaliadas apresentam potencial para serem conservadas na forma de silagem, pois todas apresentaram parâmetros de fermentação desejáveis. No entanto, a variedade BR 5028 São Francisco seria a menos indicada em virtude das suas características de composição bromatológica e DIVMS.

\section{REFERÊNCIAS BIBLIOGRÁFICAS}

ABDELHADI, L.O.; SANTINI, F.J.; GAGLIOSTRO, G.A. Corn silage or high moisture corn supplements for beef heifers grazing temperate pastures: effects on performance, ruminal fermentation and in situ pasture digestion. Anim. Feed Sci. Technol., v.118, p.63-78, 2005.

CABRAL, L.S.; VALADARES FILHO, S.C.; DETMANN, E. et al. Taxas de digestão das frações proteicas e de carboidratos para as silagens de milho e de capim-elefante, o feno de capim-tífton 85 e o farelo de soja. Rev. Bras. Zootec., v.33, p.1573-1580, 2004. 
CALABRO, S.; CUTRIGNELLI, M.I.; PICCOLO, G. et al. In vitro fermentation kinetics of fresh and dried silage. Anim. Feed Sci. Technol., v.123, p.129-137, 2005.

CHARACTERIZATION of feedstuffs - AFRC. Technical committee on responses to nutrients. (Report 2). Nutr. Abstr. Rev., Series B, v.57, p.713736, 1987.

CONTRERAS-GOVEA, F.E.; MUCK, R.E.; ARMSTRONG, K.L. et al. Nutritive value of corn silage in mixture with climbing beans. Anim. Feed Sci. Technol., v.150, p.1-8, 2009.

COSTA, C.; CRESTE, C.R.; ARRIGONI, R.B. et al. Potencial para ensilagem, composição química e qualidade da silagem de milho com diferentes proporções de espigas. Acta Scient., v.22, p.835-841, 2000.

DETMANN, E.; ZERVOUDAKIS, J.T.; CABRAL, L.S. et al. Validação de equações preditivas da fração indigestível da fibra em detergente neutro em gramíneas tropicais. Rev. Bras. Zootec., v.33, p.18661875, 2004.

DONMEZ, N.; KARSLY, M.A.; CYNAR, A. et al. The effects of different silage additives on rumen protozoa number and volatile fatty acid concentration in sheep fed corn silage. Small Ruminant Res., v.48, p.227-231, 2003.

FERRARI Jr., E.; POSSENTI, R.A.; LIMA, M.L.P. et al. Características, composição química e qualidade de silagens de oito cultivares de milho. Bol. Ind. Anim., v.62, p.19-27, 2005.

FILYA, I. Nutritive value of whole crop wheat silage harvested at three stages of maturity. Anim. Feed Sci. Technol., v.103, p.85-95, 2003.

JAREMTCHUK, A.R.; JAREMTCHUK, C.C.; BAGLIOLI, B. et al. Características agronômicas e bromatológicas de vinte genótipos de milho (Zea mays L.) para silagem na região leste paranaense. Acta Scient. Anim. Sci., v.27, p.181-188, 2005

JENSEN, C.; WEISBJERG, M.R.; NORGAARD, P. et al. Effect of maize silage maturity on site of starch and NDF digestion in lactating dairy cows. Anim. Feed Sci. Technol., v.118, p.279-294, 2005.

KUNG Jr., L.; RANJIT, N.K. The effect of Lactobacillus buchneri and other additives on the fermentation and aerobic stability of barley silage. $J$. Dairy Sci., v.84, p.1149-1155, 2001.
McDONALD, P.; HENDERSON, A.R.; HERON, S.J.E. The biochemistry of silage. s.l.: Scholium International, 1991. 155p.

MELLO, R.; NÖRNBERG, J.L.; ROCHA, M.G. et al. Características produtivas e qualitativas de híbridos de milho para produção de silagem. Rev. Bras. Milho Sorgo, v.4, p.79-94, 2005.

NISHIDA, T.; ERUDEN, B.; HOSODA, K. et al. Digestibility, methane production and chewing activity of steers fed whole-crop round bale corn silage preserved at three maturities. Anim. Feed Sci. Technol., v.135, p.42-51, 2007.

OFFICIAL methods of analisys. 16.ed. Washington: AOAC.

PEDROSO, S.; EZEQUIEL, J.M.B.; OSUNA, J.T.A. et al. Características agronômicas e nutricionais de híbridos de milho e suas silagens (Zea mays L.). ARS Vet., v.22, 248-258, 2006.

PEREIRA, E.S.; MIZUBUTI, I.Y.; PINHEIRO, S.M. et al. Avaliação da qualidade nutricional de silagens de milho (Zea mays, L). Rev. Caatinga, v.20, p.08-12, 2007.

ROSA, J.R.P.; SILVA, J.H.S.; RESTLE, J. et al. Avaliação do comportamento agronômico da planta e valor nutritivo da silagem de diferentes híbridos de milho (Zea mays, L.). Rev. Bras. Zootec., v.33, p.302312, 2004.

SENGER, C.C.D.; MÜHLBACH, P.R.F.; SÁNCHEZ, L.M.B. et al. Composição química e digestibilidade 'in vitro' de silagens de milho com distintos teores de umidade e níveis de compactação. Cienc. Rural, v.35, p.1393-1399, 2005.

SILVA, D.J.; QUEIROZ, A.C. Análise de alimentos: métodos químicos e biológicos. 3.ed. Viçosa: UFV, 2002. 235p.

TILLEY, J.A.; TERRY, A.R. A two-stage technique for in vitro digestion of forages crops. J. Br. Grassl. Soc., v.18, p.104-111, 1963.

TOMICH, T.R.; PEREIRA, L.G.R.; GONÇALVES, L.C. et al. Características químicas para avaliação do processo fermentativo de silagens: uma proposta para qualificação da fermentação. Corumbá: Embrapa Pantanal, 2003. 20p.

VALADARES FILHO, S.C.; MAGALHÃES, K.A.; ROCHA Jr., V.R. et al. Tabelas brasileiras de composição de alimentos para bovinos. CQBAL 2.0. Viçosa: UFV, 2006. 297p.

VAN SOEST, P.J. Nutritional ecology of the ruminant. Ithaca: Cornell University, 1994. 476p. 